\title{
Resolving the Genetic and Environmental Sources of the Correlation Between Height and Intelligence: A Study of Nearly 2600 Norwegian Male Twin Pairs
}

\author{
Jon Martin Sundet,' Kristian Tambs, ${ }^{2}$ Jennifer R. Harris, ${ }^{2}$ Per Magnus, ${ }^{2}$ and Tore M. Torjussen ${ }^{3}$ \\ 1 Institute of Psychology, University of Oslo, Oslo, Norway \\ ${ }^{2}$ The Norwegian Institute of Public Health, Oslo, Norway \\ ${ }^{3}$ Psychological Services, Norwegian Armed Forces, Oslo, Norway
}

\begin{abstract}
The main aim of this paper was to resolve the correlation between intelligence test scores and standing height into genetic and environmental components. Data on 1181 identical and 1412 fraternal twin pairs (all males) were retrieved by matching files from the Norwegian Army with twin registries. The data were analyzed by means of a structural equation model comprising latent genetic, shared environmental and nonshared environmental factors and correlations between them. A major part of the height-intelligence correlation was due to correlated shared environments $(59 \%$ of the phenotypic height-intelligence correlation), but statistically significant effects of correlated genes and nonshared environments were also found (respectively $35 \%$ and $6 \%$ of the phenotypic correlation).
\end{abstract}

Several studies have found moderate but consistently positive correlations between height and intelligence test scores (Husén, 1959; Johnson, 1991; Tanner, 1966; Teasdale et al., 1989; Tuvemo et al., 1999; Udjus, 1964). The height-intelligence correlation is apparent early in life (Humphreys et al., 1985), but it may be at least as large in adults as in children. Johnson (1991) pooled the correlations from several studies and concluded that the average height-intelligence correlation was slightly (and significantly) larger among adults than among children $(.22$ and .18 , respectively).

The height-intelligence correlation may be decreasing, at least in the Scandinavian countries. Among Norwegian conscripts born between 1950 and 1985 , it decreased quite steadily from .17 to .14 (Sundet et al., 2004). Data on Danish conscripts showed that the correlation between height and intelligence was steadily declining from the birth cohorts in the early 1940s to the cohorts in the mid 1960s (Teasdale et al., 1989). Husén (1959; cf. Tanner, 1966) reported a correlation of .22 among Swedish conscripts. Tuvemo et al. (1999) studying a more recent conscript cohort (1994), found a correlation of .14.
Several authors have discussed the relative importance of genetic and environmental factors involved in the height-intelligence correlation. Johnson (1991) reasoned that environmental conditions aggregate in social classes, implying that the height-intelligence correlation should decrease if social class is partialled out. He found that the correlation between height and intelligence was only slightly reduced when controlling for social class, and concluded that genetic factors may play a major part. In a large twin study, Husén (1959) found that the cross-trait cross-twin correlation between height and intelligence was not much higher in monozygotic (MZ) than in dizygotic (DZ) twin pairs (.33 and .25, respectively), and concluded that environmental factors seem to be of primary importance in explaining the relationship between height and intelligence.

A major step toward elucidating the nature of the relationship between height and intelligence would be to resolve the phenotypic association into component genetic and environmental pathways. This type of analysis requires data from genetically informative designs (e.g., twin studies), which can be analyzed by structural equation modeling.

The purpose of the present study is to analyze genetic and environmental sources of covariation underlying the relationship between height and intelligence using data from a large sample of Norwegian twins.

\section{Methods and Materials}

In Norway, military service is compulsory for every able young man. Females may enter the service on a voluntary basis. Before they actually enter the service the conscripts are required to meet before a draft

\section{Received 8 March, 2005; accepted 24 May, 2005.}

Address for correspondence: Jon Martin Sundet, Institute of Psychology, University of Oslo, PO Box 1094, N-0317 Blindern, Oslo, Norway.E-mail: j.m.sundet@psykologi.uio.no 
board where their medical and psychological suitability, including standing height and intellectual ability, for military service are assessed. A great majority of the men meeting before the draft board (about 95\%) are examined between their 18th and 20th birthdays. Physically or psychologically disabled are exempted from these investigations. Also, seamen and others who are abroad at the normal conscript age are normally exempted.

\section{Subjects and Data}

Twin data on height and intelligence test scores were obtained by matching a file from the Norwegian Army, comprising among other things data on height and intelligence test scores, with two Norwegian twin panels. One of them, the Norwegian Twin Panel, comprises like-sex twins born from 1915 to 1960 (Magnus et al., 1983). A continuation of the Norwegian Twin Panel (the Norwegian Institute of Public Health Twin Panel) was constructed by using data from the Norwegian Medical Birth Registry, which contains information on all the newborn children in Norway from 1967 and up to the present (Harris et al., 2002). In this panel, zygosity information was available for the birth cohorts 1967-1979, inclusive. Data on height and intelligence were retrieved for 1181 male $\mathrm{MZ}$ pairs and 1412 male DZ pairs, comprising about $50 \%$ of the MZ male twins and $59 \%$ of the DZ male twins born in the relevant period. Zygosity was ascertained using questionnaire methodology that has been shown to assign correct zygosity in more than $97 \%$ of the cases (Magnus et al., 1983).

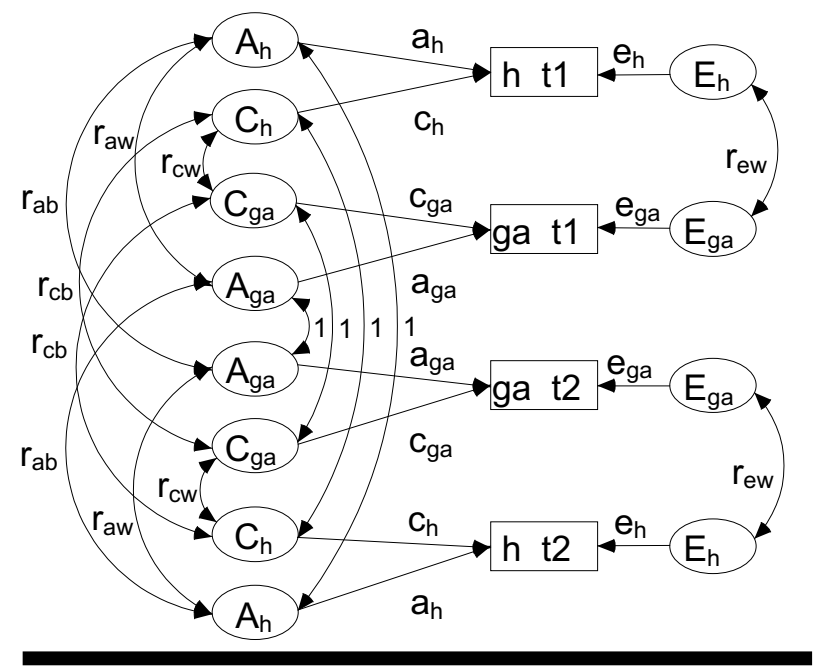

Figure 1

The full bivariate model of general ability and height for the $M Z$ twin group. $A_{h}, C_{h}, E_{h}, A_{g a}, C_{g a}$ and $E_{g a}$ denote the latent genetic, shared environments, and nonshared environments for height and general ability, respectively. $\mathrm{h} \mathrm{t} 1$ and $\mathrm{h} \mathrm{t} 2$ are the height of the two twins; ga t1 and ga t2 the general ability scores. The correlations between the $A_{h}$ 's and $A_{\text {ga }}$ 's are 1 for $M Z$ twins, and .5 for $D Z$ twins. The cross-twin cross-trait correlations between $\mathrm{A}_{\mathrm{h}}$ and $\mathrm{A}_{\mathrm{ga}}$ is $r_{a b}$ for $\mathrm{MZ}$ and $.5^{*} r_{a b}$ for DZ twins. $r_{a w}$ $r_{c w}$ and $r_{e w}$ are the within-twin cross-trait latent correlations.

For further explanation, see text.

\section{Test Materials}

Intelligence test data comprised general ability scores in stanine units according to norms from 1963. General ability is a composite score of three speeded subtests, Arithmetic, Word Similarities and Figures. The Arithmetic test, presented in prose, purports to measure arithmetic and elementary algebraic ability but also logical reasoning ability, and is quite similar to the Arithmetic test in Wechsler Adult Intelligence Scale (WAIS; Cronbach, 1964). The Word Similarities test (akin to the Vocabulary test in WAIS) is a synonym test. The Figures test was constructed to be very similar to Raven Progressive Matrices (Cronbach, 1964). The test-retest reliabilities of Arithmetic, Word Similarities and Figures tests as calculated from a sample $(N \approx 800)$ in the mid-1950s were $.84, .90$ and .72 , respectively. Internal consistency coefficients (Cronbach $\alpha$ ) were respectively, $.87, .93$ and .84 (Notes from the Norwegian Army Psychological Services, 1956). In a smallish sample $(N=48)$, the correlation between general ability and the WAIS IQ has been found to be .73, with time spans between the two tests varying from 2 to 25 years (Sundet et al., 1988).

In accordance with earlier results, the mean general ability scores and height changed over cohorts (Flynn, 1987; Sundet et al., 2004). Before computing covariances and correlations, the mean scores of height and general ability were standardized to be equal in all the cohorts.

\section{Statistical Models and Estimation Procedures}

In order to resolve the correlation between general ability and height into latent genetic and environmental correlations, a comprehensive bivariate path model for $\mathrm{MZ}$ and DZ twin data was constructed (e.g., Neale \& Cardon, 1992). The full model for identical twins is shown in Figure 1.

The model specifies that each phenotype is explained by a combination of latent genetic, shared environmental and nonshared environmental factors. The genetic contribution was specified in paths from the genetic factors for height and general ability $\left(A_{h}\right.$ and $\mathrm{A}_{\mathrm{ga}}$, respectively), with path coefficients $a_{b}$ and $a_{g a}$ to the height and general ability phenotypes of the twins ( $\mathrm{h} \mathrm{t} 1$, $h \mathrm{t} 2$, ga $t 1$ and ga $t 2$ in Figure 1). The paths from $\mathrm{C}_{\mathrm{ga}}$ and $\mathrm{C}_{\mathrm{h}}$ with the path coefficients $c_{g a}$ and $c_{h}$ to the corresponding phenotypes denote the contribution of environments shared by both twins in a pair. Effects of nonshared environments $\left(\mathrm{E}_{\mathrm{ga}}, \mathrm{E}_{\mathrm{h}}\right)$ were denoted $e_{g a}$ and $e_{b}$. The path coefficients from a given latent factor to one of the phenotypes were constrained to be equal for both twins in a pair. The cross-twin within-trait correlations between latent shared environments are unity both for MZ and DZ twins. The cross-twin within-trait correlations between the latent genetic factors were modeled based on biometric expectations ( 1 for MZ, .5 for DZ twins) that reflect the extent to which members of identical and fraternal pairs are correlated for addi- 
tive genetic effects. Nonshared environments were assumed to be uncorrelated for members of twin pairs.

The 'ordinary' intraindividual correlation between height and general ability (within-twin cross-trait correlation) was specified in terms of correlations between the latent genetic, shared environmental and nonshared environmental factors of height and the corresponding latent factors of general ability (respectively, $r_{a w}, r_{c w}$ and $r_{e w}$ in Figure 1). The latent genetic correlation between $\mathrm{MZ}$ twins (cross-trait cross-twin correlation) denoted $r_{a b}$ (Figure 1), was constrained to be equal to the within-twin cross-trait correlation $\left(r_{a w}\right.$ in Figure 1). For DZ twins, this correlation was constrained to be half the within-twin cross-trait genetic correlation (i.e., . $\left.5^{*} r_{a w}\right)$. Shared environments correlations across twins $\left(r_{c b}\right.$ in Figure 1$)$ were specified to be equal to the within-twin cross-trait shared environments correlation $\left(r_{c w}\right.$ in Figure 1$)$. Nine parameters were estimated in the full model. Six of these are the path coefficients from the latent factors to general ability and height $\left(a_{g a}, c_{g a}, e_{g a}, a_{b}, c_{b}, e_{b}\right)$. The other three are the correlations between the latent factors $\left(r_{a w}, r_{c w}\right.$ and $\left.r_{e w}\right)$.

Under this model, expected genetic, shared and nonshared environmental correlations between the general ability and height phenotypes may be readily calculated by the path multiplication rules derived by Sewell Wright (e.g., Neale \& Cardon, 1992). For instance, using standardized path coefficients, the genetic correlation between general ability and height is $a_{g a}{ }^{*} r_{a w}{ }^{*} a_{b}$ (cf. Figure 1). Heritabilites, shared and nonshared environmental effects on general ability and height may be calculated by squaring the appropriate (standardized) path coefficients.

Parameter estimates were obtained using LISREL, version 8.50 (Jöreskog \& Sörbom, 1993). LISREL supplies maximum likelihood estimates and offers a number of fit indices. We have chosen the traditional chi-square statistic together with the Root Mean Square Error of Approximation (RMSEA) index.

A full model estimating path coefficients for genetic, unshared and shared environments together with the correlations between them was fitted first. To test the significance of the effects mediating the correlation between the phenotypes three reduced models were tested that constrained each of the latent correlations, $r_{a w}\left(\right.$ and $\left.r_{a b}\right), r_{c w}\left(\right.$ and $\left.r_{c b}\right)$, and $r_{e w}$, to zero.

\section{Results}

Descriptive statistics on the nontwins, identical and fraternal twins are shown in Table 1 . The mean general ability and mean height were significantly larger $(p<.001)$ in the nontwin group than among the twins. The standard deviation of general ability was slightly, but significantly $(p<.001)$ smaller among nontwins, whereas the standard deviation of height was slightly larger $(p<.001)$. The mean general ability score was significantly higher among MZ than DZ twins $(p<.001)$, whereas the mean height was signifi-

\section{Table 1}

Means and Standard Deviations of General Ability (in Stanine Units) and Height Among Nontwins, MZ and DZ Twins

\begin{tabular}{lcclccl}
\hline & \multicolumn{3}{c}{ General ability } & \multicolumn{3}{c}{ Height } \\
\cline { 2 - 7 } & $M$ & $S D$ & $N$ & $M$ & $S D$ & \multicolumn{1}{c}{$N$} \\
\hline Nontwins & 6.08 & 1.61 & 926,772 & 179.35 & 6.62 & $1,003,443$ \\
MZ & 5.96 & 1.64 & 2617 & 178.65 & 6.41 & 2708 \\
$D Z$ & 5.80 & 1.69 & 3274 & 179.12 & 6.56 & 3436 \\
\hline
\end{tabular}

\section{Table 2}

MZ (Upper Triangle) and DZ Correlations (Lower Triangle) for $1181 \mathrm{MZ}$ and $1412 \mathrm{DZ}$ Pairs

\begin{tabular}{lllll}
\hline & 1 & 2 & 3 & 4 \\
\hline 1. General ability-twin1 & - & .18 & .81 & .16 \\
2. Height-twin1 & .18 & - & .19 & .92 \\
3. General ability-twin2 & .51 & .13 & - & .20 \\
4. Height-twin2 & .12 & .54 & .16 & \\
\hline
\end{tabular}

cantly lower among MZ twins $(p<.01)$. The standard deviations of the general ability and height were larger in the $\mathrm{DZ}$ than in the $\mathrm{MZ}$ group, but these differences did not quite reach statistical significance.

The correlation between height and general ability in the nontwin part of the sample was .15 . Correlation matrices of general ability and height for $\mathrm{MZ}$ and DZ twins are shown in Table 2.

The within-twin cross-trait correlation was slightly larger in the MZ group than in the DZ group, but not significantly so (Table 2 ). The cross-twin cross-trait correlations between general ability and height for MZ and DZ twins are of special interest in this context. It is seen from Table 2 that the crosstwin cross-trait correlations for MZ twins were almost as high as the within-twin cross-trait correlations. The cross-twin cross-trait correlation for $\mathrm{MZ}$ was higher than the cross-twin cross-trait DZ correlation, the $\mathrm{DZ}$ correlation being $71.4 \%$ of the $\mathrm{MZ}$ correlation (Table 2).

LISREL estimates were obtained using the variance-covariance matrices as input. The full model with genetic, shared environments and nonshared environmental effects (the ACE-model) fit the data very well $\left(\chi_{11}^{2}=11.97, p=.37, \mathrm{RMSEA}=.008\right)$.

A reduced model constrained the correlation between nonshared environments of height and general ability $\left(r_{e w}\right)$ to zero. The fit deteriorated significantly when compared to the full model $\left(\chi_{1}^{2}=13.24\right.$, $p<.001)$. Next, a reduced model with zero $r_{c w}$ (and zero $\left.r_{c b}\right)$ fit even worse $\left(\chi^{2}{ }_{1}=15.86, p<.001\right)$. Constraining the genetic correlation $r_{a w}\left(\right.$ and $r_{a b}$ ) to zero also worsened the fit significantly relative to the full model $\left(\chi^{2}{ }_{1}=6.32, p<.02\right)$. Consequently, the results from the full ACE model were accepted. The 
correlation patterns (Table 2) do not indicate dominance variation, so models allowing for dominance effects were omitted.

LISREL estimates of the path coefficients and the corresponding heritabilities $\left(a^{2}\right)$, and variance estimates for the shared and nonshared environmental effects $\left(c^{2}\right.$ and $e^{2}$, respectively) of height and general ability from the full model are shown in Table 3. The correlations between the latent genetic, shared and nonshared environments variables and the corresponding phenotypic components of the correlation between general ability and height are shown in Table 4. As may be seen from the standard errors (Tables 3 and 4), the path coefficients and the correlations between the latent factors differed significantly from zero.

The values in Table 4 indicate that the correlation between the latent shared environments factor was by far the largest followed by the nonshared and genetic latent factors. The phenotypic component of the shared environments factor accounted for about $59 \%$ of the total height-general ability correlation. The corresponding contributions of the genetic and the nonshared environments factors were $35 \%$ and $6 \%$, respectively.

\section{$\overline{\text { Discussion }}$}

Considering the substantial correlation between the general ability score used in the present study and WAIS IQ $(r=.73$, with several years between measurements) found in Norwegian data, it is likely that the results found in the present paper may be generalized

\section{Table 3}

Full Model Estimates of the Standardized Path Coefficients $a, c$ and $e$, Standard Errors (in Parentheses), and the Corresponding Heritabilities $\left(a^{2}\right)$ Shared $\left(c^{2}\right)$ and Nonshared Environmental Effects $\left(e^{2}\right)$ for General Ability and Height

\begin{tabular}{lcccccccccc}
\hline & $a$ & & $c$ & & $e$ & & $a^{2}$ & $c^{2}$ & $e^{2}$ \\
\hline General ability & .80 & $(.02)$ & .43 & $(.04)$ & .42 & $(.01)$ & .64 & .18 & .18 \\
Height & .87 & $(.02)$ & .40 & $(.05)$ & .28 & $(.01)$ & .76 & .16 & .08 \\
\hline
\end{tabular}

\section{Table 4}

The Correlations Between the Latent Genetic, Shared Environment and Nonshared Environments of General Ability and Height (Standard Errors in Parentheses ), and the Genetic, Shared and Nonshared Environmental Components of the Phenotypic Correlation Between General Ability and Height

\begin{tabular}{lllc}
\hline & & & $\begin{array}{l}\text { Phenotypic } \\
\text { components }\end{array}$ \\
\hline Genetic & .09 & $(.04)$ & .06 \\
Shared env. & .56 & $(.16)$ & .10 \\
Nonshared env. & .12 & $(.03)$ & .01
\end{tabular}

to standard intelligence test scores. The twin sample includes more than half of the male twins born in the actual period. Attrition was mostly due to selection in the twin panel and missing intelligence and height data on one or both twins. However, because these results are based on population-based data, the present sample may be more representative than the samples available in many twin studies.

In accordance with earlier results (e.g., Husén, 1959), we found lower mean values for intelligence scores and height among the twins compared to the nontwin group (Table 1). This may reflect disadvantages experienced by twins because they share prenatal environments. The rather small difference between the height-intelligence correlation in the twin and nontwin group (.15 and .18 respectively) may not affect the generalizability of the results of the structural equation modeling of twin data to the general population appreciably.

Another potential problem in twin studies is that genetic correlations between the parents due to assortative mating with regard to intelligence and/or height will be distributed as shared environments, possibly inflating the correlation between shared environmental effects. In Norway, spouses have been found to correlate both with regard to intelligence $(.32)$ and height (.18; Tambs, Moum, et al., 1992; Tambs, Sundet, et al., 1992; respectively). To assess the possible effects of assortative mating on twin correlations, data from extended families (e.g., twins and their parents) on height and intelligence are needed.

The estimates from the bivariate model (Table 4) show that correlated genes, correlated shared and nonshared environments all contribute significantly to the general ability-height correlation. The latent shared environments correlation was by far the largest, followed by nonshared environments and genetic correlations (Table 4). The nonshared environments and genetic correlations were of the same order of magnitude, and the difference between them is not statistically significant. The heritabilities of general ability and height by far outsized the contributions of shared and nonshared environments (Table 3). Consequently, the genetic component of the ability-height correlation was larger than the nonshared environments component (Table 4). Thus, the genetic correlation component accounted for $35 \%$ of the total phenotypic intelligence-height correlation, whereas the nonshared environments component accounted for $6 \%$. The rest $(59 \%)$ was accounted for by the shared environments correlation component. The genetic correlation may seem to be smaller than often conjectured.

The substantial environmental contributions to the height-intelligence correlation found in the present study and by Husén (1959) may indicate that environmental factors influencing intelligence and height go together, possibly both prenatally and postnatally. For example, some mothers may provide better prenatal 
conditions for their children than others. Also, some parents may provide both more cognitive stimulation and more adequate nutrition. Secular trends show increases in height and intelligence in numerous countries. This co-patterning may be explained, at least in part, by common childhood environmental influences implicated in growth and development. Lynn (1990) proposed that nutrition might be such a factor. Nutrition may be a potent common factor in developing countries, and may have been so in the industrialized countries in earlier times. However, a recent study suggested that the secular increases in height and intelligence in more recent cohorts are not caused by nutrition as a common factor to height and intelligence (Sundet et al., 2004).

The declining height-intelligence correlation observed in studies of military conscripts in the Scandinavian countries (Sundet et al., 2004; Tanner, 1966, Teasdale et al., 1989; Tuvemo et al., 1999) may, at least partly, be attributed to a decrease in the shared environment correlation component. This could partly be due to improving availability of prenatal care, and a more general awareness among becoming mothers of the potential dangers of smoking and drinking during pregnancy. Also, an increasing awareness of the importance of cognitive stimulation and proper nutrition may have been involved. If so, the shared environmental component of the correlation between height and intelligence might be expected to be smaller in future studies. To the extent that the correlation between spouses with regard to intelligence or/and height changes over time, the genetic part of the height-intelligence may change.

The present data set comprises only adult males. The situation may be different for females. Studies of children and older adults may also prove enlightening. Studies clarifying the factors influencing intelligence and height may also be highly rewarding.

\section{Acknowledgments}

The authors are indebted to the Norwegian Armed Forces for kindly making data used in this paper available to us.

\section{References}

Cronbach, L. J. (1964). Essentials of psychological testing (2nd ed.). London: Harper \& Row.

Flynn, J. R. (1987). Massive IQ gains in 14 nations: What IQ tests really measure. Psychological Bulletin, 101, 171-191.

Harris, J. R., Magnus, P., \& Tambs, K. (2002). The Norwegian Institute of Public Health Twin Panel: A description of the sample and program of research. Twin Research, 5, 415-423.
Humphreys, L. G., Davey, T. C., \& Park, R. K. (1985). Longitudinal correlation analysis of standing height and intelligence. Child Development, 56, 1465-1478.

Husén, T. (1959). Psychological twin research. Stockholm, Sweden: Almqvist and Wiksell.

Johnson, F. W. (1991). Biological factors and psychometric intelligence: A review. Genetic, Social, and General Psychology Monographs, 117, 315-357.

Jöreskog, K. G., \& Sörbom, D. (1993). LISREL 8 User's reference guide. Chicago: SSI.

Lynn, R. (1990). The role of nutrition in the secular increases of intelligence. Personality and individual differences, 11, 273-286.

Magnus, P., Berg, K., \& Nance, W. E. (1983). Predicting zygosity in Norwegian twin pairs born 1915-1960. Clinical Genetics, 24, 103-112.

Neale, M. C., \& Cardon, L. R. (1992). Methodology for genetic studies of twins and families. Dordrecht, the Netherlands: Kluwer Academic.

Notes from the Psychological Services of the Norwegian Armed Forces [in Norwegian]. (1956). Memorandum 12B. Oslo, Norway: Psychological Services, Norwegian Armed Forces.

Sundet, J. M., Tambs, K., Magnus, P., \& Berg, K. (1988). On the question of secular trends in the heritability of IQ test scores: A study of Norwegian twins. Intelligence, 12, 47-59.

Sundet, J. M., Barlaug, D., \& Torjussen, T. M. (2004). The end of the Flynn Effect? A study of secular trends in mean intelligence test scores of Norwegian conscripts during half a century. Intelligence, 32, 349-362.

Tambs, K., Moum, T., Eaves, L. J., Neale, M. C., Midthjell, K., Lund-Larsen, P. G., \& Næss, S. (1992). Genetic and environmental contributions to the variance of body height in a sample of first and second degree relatives. American Journal of Physical Anthropology, 88, 285-294.

Tambs, K., Sundet, J. M., \& Berg, K. (1992). Correlations between identcal twins and their spouses suggest social homogamy for intelligence in Norway. Personality and Individual Differences, 14, 279-281.

Tanner, J. M. (1966). Galtonian eugenics and the study of growth. Eugenics Review, 58, 122-135.

Teasdale, T. W., Sørensen, T. I. A., \& Owen, D. R. (1989). Fall in association of height with intelligence and educational level. British Medical Journal, 298, 1292-1293.

Tuvemo, T., Jonsson, B., \& Persson, I. (1999). Intellectual and physical performance and morbidity in relation to height in a cohort of 18-year-old Swedish conscripts. Hormone Research, 52, 186-191.

Udjus, L. G. (1964). Anthropometrical changes in Norwegian men in the twentieth century. Oslo, Norway: Universitetsforlaget. 